KS. WŁODZIMIERZ BIELAK* - LUBLIN

\title{
DOKUMENT FUNDACYJNY KLASZTORU KANONIKÓW REGULARNYCH LATERAŃSKICH W KRAŚNIKU
}

Klasztor kanoników regularnych w Kraśniku powstał w latach sześćdziesiątych XV wieku. W roku 1468 Jan Rabsztyński h. Topór zdecydował się przekształcić kościół parafialny w klasztorny. Dokument fundacyjny wystawił 18 maja tego roku. Biskup krakowski Jan Lutek z Brzezia zatwierdził fundację 13 marca $1469 \mathrm{roku}^{1}$. Zatwierdzenie papieskie klasztor otrzymał w $1487 \mathrm{roku}^{2}$. Pierwsi zakonnicy przybyli do Kraśnika z klasztoru Bożego Ciała w Krakowie. Klasztor funkcjonował do kasaty w 1864 roku. Od tej pory do dziś kościół pokanonicki jest kościołem parafialnym.

Wystawcą dokumentu jest Jan Rabsztyński ${ }^{3}$ herbu Topór, syn i dziedzic zamordowanego w 1461 roku Andrzeja Tęczyńskiego ${ }^{4}$. $Z$ treści dokumentu wynika, że fundacja klasztoru w Kraśniku była poczyniona w intencji zbawienia ojca, Andrzeja („pro salute olim magnifici viri domini Andree de Thanczyn”). Naśladował więc Jan Rabsztyński swego rodzica, który ufundował kaplicę w kościele parafialnym w Książu za zbawienie duszy zmarłej w 1458 roku żony, Jadwigi z Książa. Nota bene współfundatorem tej kaplicy był jej syn, Jan Rabsztyński ${ }^{5}$. Śmierć Andrzeja Tęczyńskiego poniekąd umożliwiła utworzenie klasztoru kraśnickiego, bowiem, jak słusznie przypuszcza J. Kurtyka, fundusze na ten cel pochodziły

* Ks. Włodzimierz Bielak - dr hab. historii Kościoła; adiunkt w Katedrze Historii Kościoła w Starożytności i Średniowieczu, Instytut Historii Kościoła i Patrologii KUL; e-mail: bielakwl@kul.pl

${ }^{1}$ Archiwum Narodowe w Krakowie, Perg. 889.

${ }^{2} \mathrm{Z}$ polecenia papieża Innocentego VIII fundację zbadał i dokument wystawił Jan Breynner, opat koprzywnicki. Archiwum Narodowe w Krakowie, Perg. 898.

${ }^{3}$ Jan Rabsztyński - fundator klasztoru kanoników regularnych w Kraśniku. Był synem Andrzeja Tęczyńskiego i córki Jana z Melsztyna, Jadwigi z Książa, oraz bratankiem kasztelana krakowskiego Jana Tęczyńskiego. J. Kurtyka, Tęczyńscy - studium z dziejów polskiej elity możnowładczej w średniowieczu, Kraków 1997, s. 571-573).

${ }^{4}$ Andrzej Tęczyński - ojciec Jana Rabsztyńskiego, fundatora klasztoru kraśnickiego. Zamordowany przez mieszczan krakowskich 16 VII 1461 roku. Zajście szczegółowo opisuje Jan Długosz, Roczniki czyli kroniki sławnego Królestwa Polskiego, księga 12, Warszawa 2009, s. $401 \mathrm{nn}$.

${ }^{5}$ Kurtyka, Tęczyńscy, s. 501, 572. 
z odszkodowania za zabicie Andrzeja Tęczyńskiego wypłaconego przez miasto Kraków Tęczyńskim ${ }^{6}$.

Ze słów Jana Rabsztyńskiego możemy wnioskować, że z zamiarem osadzenia w Kraśniku zakonników nosił się już jego ojciec (,cuius animus, dum aduc in humanis agebat, fervencius et intimius ad hoc estuabat et quottidie hoc perficere cogitabat, nec non successorum meorum ac heredum peccaminum remedio"), lecz nagła śmierć pokrzyżowała te plany, a ich realizacja przypadła synowi. Inne motywy fundacji wymienione w dokumencie należy uznać za zwyczajowe zwroty mające świadczyć o dewocyjnych pobudkach donatora, bo przecież ostatecznie i o zbawienie jego własnej duszy tutaj chodziło. Zwraca jednak uwagę troska Jana Rabsztyńskiego o zapewnienie swoim poddanym należytej opieki duszpasterskiej (,conventum virorum religiosorum, qui divina diurna pariter et nocturna officia possent peragere, et sua vita laudabili pariter et doctrina salubri populum Dei sibi commissum in viam possint dirigere salutis ceterisque christifidelibus sua conversacione laudabili in normam esse et exemplum") i to, jak się wydaje, w duchu torującej sobie drogę w XV w. devotio moderna, w której tak istotny był przykład życia duszpasterzy. Tym wymaganiom niewątpliwie mogli sprostać kanonicy regularni cieszący się w tamtym czasie powszechnym uznaniem i otwarci na nowe formy pobożności ${ }^{7}$.

Fundacja klasztoru odbyła się za wyraźną radą kasztelana krakowskiego Jana Tęczyńskiego ${ }^{8}$, który, po upadku obozu oligarchicznego i utratą dawnych wpływów w państwie, zajął się sprawami rodzinnymi ${ }^{9}$, w tym zapewne wspierał swego bratanka, Jana Rabsztyńskiego. Udział Jana Tęczyńskiego w tworzeniu klasztoru mógł być jednak przyczyną zwłoki biskupa Jana Lutka z Brzezia w zatwierdzeniu fundacji. Biskup uczynił to w niezwyczajnie długim dla takich spraw terminie, bo dopiero 10 miesięcy później. Być może pamiętał Janowi Tęczyńskiemu jego stanowisko w zatargu o biskupstwo krakowskie, w którym kasztelan krakowski, wbrew wyborowi kapituły (Jan Lutek z Brzezia) i woli króla Kazimierza Jagiellończyka optującego za Janem Gruszczyńskim, poparł Jakuba z Sienna ${ }^{10}$.

Prezentowany dokument jasno określa uposażenie nowo powstającego klasztoru, które wystarczająco zostało już omówione w opracowaniach ${ }^{11}$.

Nieznane jest miejsce wystawienia niniejszego dyplomu. Biorąc jednak pod uwagę udział kasztelana krakowskiego Jana Tęczyńskiego przy fundacji, można domniemywać, że dokument ten mógł powstać w jego kancelarii, tym bardziej, że Jan Rabsztyński nie pełnił w 1468 roku żadnych urzędów.

${ }^{6}$ Tamże, s. 382 .

${ }^{7} \mathrm{Na}$ temat devotio moderna i związków z nią kanoników regularnych: W. Bielak, Devotio moderna $w$ polskich traktatach duszpasterskich powstatych $w$ środowisku krakowskim do połowy XV wieku, Lublin 2002.

${ }^{8}$ Jan Tęczyński - kasztelan krakowski (1459-1470), stryj Jana Rabsztyńskiego, fundatora klasztoru kraśnickiego. Zmarł 6 VII 1470 roku. Kurtyka, Tęczyńscy, s. 549-552, passim.

${ }^{9}$ Kurtyka, Tęczyńscy, s. 382

${ }^{10}$ Ten zatarg opisuje Kurtyka, Tęczyńscy, s. 371-380.

${ }^{11}$ Np. E. Zielińska, Kultura intelektualna kanoników regularnych z klasztoru w Kraśniku w latach 1469-1563, Lublin 2002. 


\section{Podstawa wydania}

Za podstawę wydania przyjęto rękopis przechowywany obecnie w Archiwum Narodowym w Krakowie, sygnatura: Perg. 887. Zapiski na odwrociu dokumentu świadczą, że był on przechowywany w archiwum klasztornym w Kraśniku najprawdopodobniej aż do kasaty klasztoru w 1864 roku. Biskup chełmski Wojciech Skarszewski, przeprowadzając wizytację generalną parafii kraśnickiej, zanotował: „In oppido Krasnik die 13 septembris Anno Domini 1801 sub tempus [s] visitationis nostrae generalis ecclesiae parochialis krasnicensis productum [?]. Adalbertus Episcopus manu propria”. Z początku XVIII wieku pochodzi notatka notariusza kraśnickiego, Andrzeja Koźmiana: „Reproductum in termino condescensionis feria quinta in crastino Festi Sanctorum Petri et Pauli Apostolorum Anno Domini millesimo septingentesimo vigesimo nono. Andreas Kozmian notarius cras(nicensis)".

Ten manuskrypt, potwierdzający fundację dokonaną przez Jana Rabsztyńskiego, przeznaczony dla odbiorcy i będący w posiadaniu klasztoru kanoników regularnych w Kraśniku, stanowiący podstawę jego funkcjonowania i stanu posiadania, należy uznać za oryginał i jako taki powinien stanowić podstawę niniejszego wydania.

Kopia dokumentu, znajdująca się w Bibliotece Jagiellońskiej ${ }^{12}$, zawiera jedynie część tekstu - lewa strona dokumentu została odcięta. W większości zachowany w kopii tekst, poza nieistotnymi odchyłkami, dokładnie odpowiada oryginałowi; są to następujące ustępy:

Inc. Reverendissimo in Cristo Patri et Domino.

Expl. et amodo abrogato et extincto, in regularem conventualemque.

Inc. ea disciplina, forma, regula, ordine et observancia.

Expl. millesimo quadringentesimo sexagesimo octavo.

Znaczące różnice dotyczą tej części, w której zapisano uposażenie fundowanego klasztoru. Wskazują one na dokonanie streszczenia tegoż fragmentu. Szczegółowe porównanie treści obu zapisów jest jednak niemożliwe.

\section{Nota edytorska}

Przy edycji poniższego tekstu dokumentu starano się zastosować wskazania Instrukcji wydawniczej dla średniowiecznych źródeł historycznych, w: Archiwum Komisji Historycznej, seria 2, t. 2, Kraków 1930, s. 1-40.

W szczególności, zachowano oryginalną pisownię dokumentu. Odstępstwa od powszechnie obowiązujących zasad pisowni łacińskiej zaznaczono w tekście poprzez $[s]$. Dopełniacz rzeczowników rodzaju żeńskiego pisany z końcówką -e zamiast -ae pozostawiono bez zaznaczania w tekście, bowiem taka pisownia była częstą praktyką w łacinie średniowiecznej; podobnie nie zaznaczano stosowania -ci- zamiast -ti-. Nagminne opuszczanie zdwojonych spółgłosek -cc-, -mm-, -ppzaznaczono przez dodanie brakujących liter w nawiasie okrągłym.

\footnotetext{
${ }^{12}$ Rkp. Dypl. 387.
} 
Jan Rabsztyński h. Topór prosi biskupa krakowskiego Jana Lutka z Brzezia o przeksztatcenie kościoła parafialnego w Kraśniku w kościót klasztorny Kanoników Regularnych Laterańskich, nadaje uposażenie oraz określa jego zwiazki z Klasztorem Bożego Ciała w Krakowie.

Oryg. Archiwum Narodowe w Krakowie sygnatura: Perg. 887.

Kop. Biblioteka Jagiellońska w Krakowie sygnatura: Rkp. Dypl. 387.

Reverendissimo in Cristo Patri et Domino, Domino Joanni ${ }^{13}$ Dei gratia episcopo Cracoviensi Johannes Rapstinsky de Thanczyn, heres in Krasznyk ${ }^{14}$, filialem reverenciam promptitudinemque ad quevis beneplacita paratissimam. Ad rei memoriam sempiternam. Reverendissime Pater, quamquam divine sublimitatis immensitas sublimis et immensa sue maiestatis celsitudo a qua cunctis entibus datur esse et vivere secundum diversos perfectionis gradus derivatum, propter sui sufficienciam, que cunctorum bonorum summum comprehendit, propterque sui excellenciam, que omnium laudum excedit preconia, nec egeat, nec sufficiat mortalium laudibus et honoribus predicari et extolli, humanum tamen genus lumine sui wltus $[s]$ insignitum ac racionis munere preditum creatisque aliis prepositum et prelatum debet et tenetur. Nichilominus $[s]$ iuxta potencie sue vires tante largitati largiflue grata devocione occurrere et suo Creatori debiti honoris cultu merito respondere cum itaque ec(c)lesia parochialis in op(p)ido meo Krasznyk, cuius per mortem honorabilis domini Andree ${ }^{15}$ eiusdem ultimi et immediati rectoris, de presenti accidit vacacio. Que quidem ec(c)lesia in suis proventibus ita habundat et est per predecessores meos sufficienter dotata, ut non solum ad fovendum aliquos in pauco numero presbiteros, verum eciam ad tenendum collegium sive conventum virorum religiosorum, qui divina diurna pariter et nocturna officia possent peragere, et sua vita laudabili pariter et doctrina salubri populum Dei sibi com(m)issum in viam possint dirigere salutis ceterisque christifidelibus sua conversacione laudabili in normam esse et exemplum. Proinde ego, ad quem ius patronatus et presentandi eiusdem ec(c)lesiae pro hac vice pertinere dinoscitur, considerans magis divino cultui salutique animarum expedire ibi multos fieri presbiteros quam paucos ac eciam pocius cedere ad decorem, profectum, pariter et honorem dicti loci, ut ibi sit collegium sive conventus virorum religiosorum, quorum vita et religio $\operatorname{com}(\mathrm{m})$ endabilis tanquam lucerna super candelabrum posita multis luceat in esse $[s]$ honori salutique mee, dum et utilitati private publicum profero pro divini cultus et bonorum augmento, meaque meorum predecessorum et presertim pro salute olim magnifici viri domini Andree de Thanczyn, divi recordii progenitoris mei

${ }^{13}$ Jan Lutek z Brzezia - był biskupem krakowskim w latach 1464-1471. B. Kumor, Dzieje diecezji krakowskiejdo roku 1795, t. 1, Kraków 1998, s. 509-510.

${ }^{14}$ Kraśnik - dziś miasto powiatowe w województwie lubelskim. Tęczyńscy otrzymali je wraz z posagiem córki Dymitra z Goraja, Anny, którą wydano za mąż w 1407 lub 1408 roku za Andrzeja z Tęczyna, dziadka Jana Rabsztyńskiego, fundatora klasztoru kraśnickiego. Kurtyka, Tęczyńscy, s. 275,545 .

${ }^{15}$ Andrzej Tęczyński, zob. przypis 4. 
carissimi, cuius animus, dum aduc $[s]$ in humanis agebat, fervencius et intimius ad hoc estuabat et quottidie hoc perficere cogitabat, nec non pro successorum meorum ac heredum peccaminum remedio. Ad id eciam carissimi patrui mei, magnifici domini Johannis de Thanczyn castellani Cracoviensis, votis ac consiliis et intercessionibus sollicitissimis me moventibus animum meum et voluntatem ad id libenter appono et presentibus realiter et effectualiter assencor, ut ec(c)lesia prefata in Krasznyk, que hactenus parrochialis $[s]$ extiterat, titulo dicte ec(c)lesie parrochialis $[s]$ et plebanatus iam et amodo abrogato et extincto, in regularem conventualemque $\operatorname{com}(\mathrm{m})$ utatur, transferatur et erigatur. Quapropter ego, ad quem ius patronatus hactenus pertinebat, omnibus et singulis praesencium noticiam habituris notum facio, quoniam pro fundacione ec(c)lesieque dicte in honorem Omnipotentis Dei ac Virginis Gloriose Sanctorumque Omnium de parrochiali $[s]$ in conventualem erectionem do, et perpetuis temporibus confero, pro eadem ec(c)lesia omnes eiusdem ec(c)lesie proventus ab antiquo eidem annexos. Primo et principaliter circa eandem ec(c)lesiam domum plebanalem et circa hanc aream pro edificacione domus conventualis cum orto eidem adiacenti. Item predium in suburbio platee Sandomiriensis. Item aream sive predium in loco, qui dicitur Passzyeczna Wolya ${ }^{16}$ et agrum alias nywa ex opposito eiusdem aree inter agrum Petri Brzany parte ex una, et inter agrum Passzyeczny parte ex altera, incipiens a fluvio, qui fluit de Szthroza ${ }^{17}$, per progressum in longitudinem civilium agrorum. Item villam Rzeczycza ${ }^{18}$ molendino piscinis, agris, pratis, silvis, gaiis, rubetis, quercetis, pascuis, domibus, ortis et pertinenciis universis, prout predicta villa in suis graniciebus est circumferencialiter est limitata. Item decimam peccunialem in op(p)ido Krzasznyk et in suburbio utroque de viginti laneis, in Szthroza de sexaginta laneis, in Pyassek de quatuor laneis. Item post fluvium versus Pyassek de tribus laneis Pyothraszkowszkye. In Szuchynya de omnibus agris, de quolibet predictorum mansorum sive laneorum sex grossos communis peccunie $[s]$ in regno currentis. Item granalia alias kopczyszna ${ }^{19}$ de quolibet laneo, videlicet op(p)idi

${ }^{16}$ Pasieka - późniejsza glosa marginalna na dokumencie objaśnia: „Pasieczna Wola modo vulgo vocatur Pasieka”. Nazwa Pasieka przyjęła się prawdopodobnie w XVII wieku. Ta wieś należała do dóbr parafii, a następnie, od 1468 roku, do klasztoru kanoników regularnych w Kraśniku, co wynika z niniejszego dokumentu fundacyjnego. Dziś wieś w powiecie kraśnickim, w województwie lubelskim. Na jej temat: Stownik Geograficzny Królestwa Polskiego i Innych Krajów Stowiańskich (dalej: SGKP), red. B. Chlebowski, W. Walewski, t. 7, Warszawa 1886, s. 882-883, nr 9; S. Kuraś, Stownik historyczno-geograficzny województwa lubelskiego w średniowieczu, w: Dzieje Lubelszczy$z n y$, red. T. Mencel i in., t. 3, Warszawa 1983, s. 271-272.

${ }^{17}$ Stróża - wieś w powiecie kraśnickim, w województwie lubelskim. Wymieniona w 1325 roku jako siedziba parafii katolickiej. Od 1377 roku należała do dóbr kraśnickich przekazanych Gorajskim przez króla Ludwika Węgierskiego, a następnie do Tęczyńskich. SGKP, t. 11, s. 410, nr 5, Kuraś, Stownik, s. 224.

${ }^{18}$ Rzeczyca - wieś w powiecie kraśnickim, w województwie lubelskim, dziś siedziba parafii rzymskokatolickiej w archidiecezji lubelskiej. SGKP, t. 10, s. 133, nr 7 (Rzeczyca Księża); Kuraś, Stownik, s. 207 (Rzeczyca Plebania).

${ }^{19}$ Kopczyzna - forma daniny płacona w naturze. 
Krasznyk suburbii, Szthroza, Pyassek ${ }^{20}$, Szuchynya ${ }^{21}$, tres cassulas segetum, videlicet unam siliginis, tritici alteram, avene terciam. Item in Wyszyanka ${ }^{22}$ decimam manipularem incipiens a laneo Johannis Wrobl usque ad laneum Kochanowszky, non tamen ex integro, sed incipiendo a villa usque ad montem adiacentem per transversum agrorii versus Olbyaczyn ${ }^{23}$. Item de agris scultecie eiusdem ville versus Wrzadow ${ }^{24}$, decima manipularis. Item de omnibus agris arrature $[s]$ mee in Wysznycza ${ }^{25}$, videlicet circa curiam meam incipiendo a villa Szuchynya usque ad vepres post aggerem nove vel medie piscine decimam manipularem. Et quia de supradictis, videlicet op(p)ido et villis predicte decime ad scolasteriam Sandomiriensem exigi solet, eidem nichil $[s]$ abrogare volo, et si contingat me, vel aliquem successorum meorum, predium vel predia habere, aut denuo erigere, de agris talium prediorum decimam manipularem ec(c)lesia parochialis tollet. Item prata primum sub borra ex op(p)osito piscine post curiam in Wysznycza, aliud in Kuthky, aliud post fluvium ex opposito domus et orti plebanalis. Item op(p)idum Krasznyk cum utroque suburbio et villis meis, videlicet Szthroza, Pyassek, Szuchynya, Wyszyanka, Rzeczycza, plebanali sub obediencia predicte ec(c)lesie annecto et incorporo, et quia alie ville, videlicet Szulow ${ }^{26}$ et $Z_{\text {akrzow }}{ }^{27}$, ex antiquo eidem ec(c)lesie annexe sunt, ideo easdem hic pro insertis habere volo, ubi ex agris scultecie harum villarum ex quadam concordia inter dominum abbatem Coprzywniczensem ${ }^{28}$ et eius conventum parte ex una, et plebanum Krasznycziensem parte ex altera iam dudum factam, et cum hoc de consensu moderni abbatis domini Nicolai ${ }^{29}$ et sui conventus decimam manipularem eadem ec(c)lesia

\footnotetext{
${ }^{20}$ Piasek - nieistniejąca dziś wieś w pobliżu dawnego Kraśnika, najprawdopodobniej włączona w granice miasta. Kuraś, Stownik, s. 176.

${ }^{21}$ Suchynia - dziś wieś w powiecie kraśnickim, gminie Kraśnik, należąca do parafii Wniebowzięcia NMP w Kraśniku. SGKP, t. 11, s. 546; Kuraś, Stownik, s. 229.

${ }^{22}$ Wyżnianka - dziś wieś w powiecie kraśnickim, gminie Dzierzkowice, należąca do parafii św. Józefa Robotnika w Kraśniku. SGKP, t. 14, s. 164; Kuraś, Stownik, s. 281.

${ }^{23}$ Olbięcin - dziś wieś w powiecie kraśnickim, gminie Trzydnik Duży, siedziba parafii rzymskokatolickiej w dekanacie Zaklików, diecezja sandomierska. SGKP, t. 7, s. 445-446; Kuraś, Słow$n i k$, s. 163-164.

${ }^{24}$ Urzędów - dziś miasto w powiecie kraśnickim, siedziba gminy i parafii rzymskokatolickiej pw. św. Mikołaja. SGKP, t. 12, s. 823-827; Kuraś, Stownik, s. 251-252.

${ }^{25}$ Wyżnica - wieś w powiecie kraśnickim, gminie Dzierzkowice, należąca do parafii św. Józefa Robotnika w Kraśniku. SGKP, t. 14, s. 165; Kuraś, Słownik, s. 281.

${ }^{26}$ Sulów - dziś wieś w powiecie kraśnickim, gminie Zakrzówek, siedziba parafii rzymskokatolickiej pw. św. Rajmunda Nonnata. W chwili erygowania klasztoru kraśnickiego należała do opactwa cysterskiego w Koprzywnicy. SGKP, t. 11, s. 577-578; Kuraś, Słownik, s. 229.

${ }^{27}$ Zakrzów - dziś Zakrzówek - wieś w powiecie kraśnickim, siedziba gminy i parafii rzymskokatolickiej pw. św. Mikołaja. W chwili erygowania klasztoru kraśnickiego należała do opactwa cysterskiego w Koprzywnicy. SGKP, t. 14, s. 324-325; S. Kuraś, Słownik, s. 282-283.

${ }^{28}$ Koprzywnica - dziś miasto w województwie świętokrzyskim, powiecie sandomierskim, siedziba gminy. W XII wieku powstało tu opactwo cysterskie. SGKP, t. 4, s. 384-385.

${ }^{29}$ Mikołaj Trebnic (z Trzebnicy) - był opatem w Koprzywnicy w latach 1452-1474. S. Puławski, Katalog czyli kronika opatów xx. cystersów w Koprzywnicy, „Kronika Diecezji Sandomierskiej”, 4 (1911) nr 5, s. 136-137.
} 
percipiet. Incole eciam, videlicet op(p)idi suburbii utriusque villarumque predictarum ad sacramenta ec(c)lesiastica percipienda et divina audienda ab antiquo ad eandem ec(c)lesiam pertinere dinoscitur. Insuper columbacionem de qualibet domo per duos grossos et denarium sancti Petri, inquilini vero per grossum eidem ec(c)lesie solvere tenebuntur. In honorem Omnipotentis Dei ac Beatissime Genitricis eius Virginis Marie et beatissimi patris Augustini Confessoris et Doctoris Eximii Ordinisque eius Sanctitatis Canonicorum Regularium fratribus amodo in dicta ec(c)lesia de dicto Ordine Canonicorum assumendis et existentibus ea omnia praedicta et expressa cum pertinenciis universis ad ipsam ec(c)lesiam de iure, more et conswetudine $[s]$ concernentibus, que nunc et ex antiquo habet, vel in futuro quolibet habitura est, do, dono et confero realiter, et cum effectu donatione inter vivos irrevocabili atque perpetua. Onerando in hoc ipso meam et meorum successorum conscienciam, ne quispiam tale pium opus audeat infringere. Qui quidem canonici regulares circa predictam ec(c)lesiam dirigentur ea disciplina, forma, regula, ordine et observancia, quibus monasterium Canonicorum Regularium Ordinis Beati Augustini in Casimiria prope Cracoviam regitur, regulatur et dirigitur. Et hoc tam in ec(c)lesiasticis observanciis, videlicet cantus, modulacione, accentuacione, oracione, contemplacione, necnon et in habitu, quem in ec(c)lesia, in conventu et extra conventum per omnia gerunt. Quin eciam in omni observancia cerimonialium $[s]$ regularium iuxta eiusdem monasterii prefati statutorum posicionem, disposicionem et conswetudinem $[s]$ laudabilem, cui siquidem Monasterio Corporis Christi in omnibus regularibus, ordinacionibus et conswetudinibus $[s]$ propter eiusdem ordinis integritatem, pariter et honorem ipse conventus seu monasterium in Krasznyk subiciatur et subiaceat, sic, quod prepositus monasterii Corporis Christi pro tempore existens, tanquam ipsorum pater, a quo et dirivantur, eosdem in omnibus corrigendis corrigat et emendat, sic, quod ad minus semel infra triennium aut quociescumque necessarium fuerit per se aut per fratres suos ad hoc mittendos idoneos iuxta conswetudinem $[s]$ aliorum religiosorum locorum visitat, ibique corrigenda corrigat emendando et complanando, maiora tamen ac gravia ac difficilima, que in huiusmodi visitacione evenerint, et que per se complanare non posset, Vestre Reverendissime Paternitati deferendo, per hoc tamen visitacionem iurisdiccioni Vestre Reverendissime Paternitatis tanquam loci ordinario aut archidiacono Vestre Paternitatis non derogando et cum omnis Reipublice status profectusque in rectore capiteque consistat. Ut igitur monasterium predictum maturo prudentique possit preposito dirigi et gubernari. In fratres monasterii predicti, qui nunc, aut pro tempore fuerint, omne ius patronatus et presentandi, quod ad me hactenus, quoquomodo et ad meos successores in posterum iure hereditario pertinent, spectat et pertinuit ac pertinere posset et deberet, dono et transfundo, decernensque ad me et meos successores quoscumque nihil iuris prefati pertinere aut spectare debere in posterum et in perpetuum, sic, quod in eodem monasterio fiat libera electio et tandem presentacio pro omni tempore, quo monasterium prelibatum per cessum aut decessum prepositi, aut quovis alio modo vacare contingeret, aliumque fratrem sui conventus elegant, si inter eos valens pro rectore reperiri possit. Si autem inter eos idoneum pro rectore non haberent, extunc ad patres suos, ad Corpus Christi tanquam ad suum nidulum, unde originem 
traxerunt, ipsis virum idoneum in ipsorum prelatum postulare debent. Et ipsum sic electum aut postulatum domino episcopo Cracoviensi pro tempore existenti absque mea et successorum meorum speciali requisicione, admissione, approbacione et assensu ammodo $[s]$ temporibus perpetuis libere iuxta morem Ordinis et Domus prefate in Casimiria presentant ad huiusmodi preposituram investiendum. Et ut in exordiali huiusmodi nove plantacionis fundamento prepositus et viri religiosi ac exemplares et perfecti habeantur, honorabilem et religiosum virum, dominum Iacobum ${ }^{30}$ prepositum et religiosos fratres monasterii Corporis Christi ex intimo cordis affectu peto et ad hoc consummendum requiro, ut michi $[s]$ certum virum et fratrem religiosum in prepositum et alios fratres duntaxat pro hac unica vice inchoandum tradant et illic mittant. Quibus quidem fratribus Corporis Christi per presenciam do facultatem eundem primum prepositum eligendum et ipsum per ipsos electum Vestre Reverendissime Paternitati presentandum et ad eandem preposituram perficiendum. Quare, Reverendissime Pater, humilius, quantum valeo, rogo, ut ad honorem Dei Omnipotentis eiusque Matris Gloriosissime ac Beatissimi Augustini gratiaque auctionis cultus eiusdem altissimi salutemque meam et meorum huiusmodi donationem, erectionem, translacionem, novam fundacionem, sic, ut iam premittitur, factas admittere, approbare, nec non confirmare graciosius dignemini, decretum et auctoritatem firmitatis ac roboris eisdem apponendo et monasterium ordinis prefati illuc erigere et creare presentatumque ad illud investire. Ceteraque, que in premissis et circa premissa iuxta meam huiusmodi donacionem ordinare, specificare et perhennare [s], prout ad Paternitatis Vestre Reverendissime officium pertinet pastorale, ut sic devocio mea, sinceris concepta affectibus, suum sorciatur in omnibus effectum. Premium ab ipso Ihesu Christo in evum $[s]$ recepturi. In quorum omnium et singulorum testimonium sigillum meum est presentibus in fidem veritatis subappensum. Actum et datum proxima feria quarta post Zophie ${ }^{31}$, anno ab Incarnatione Domini millesimo quadringentesimo sexagesimo octavo.

Słowa kluczowe: Kraśnik; Kanonicy Regularni Laterańscy; Jan Rabsztyński; Jan Tęczyński; Jan Lutek z Brzezia; Mikołaj Trebnic; Jakub z Wadowic

${ }^{30}$ Jakub z Wadowic - był prepozytem klasztoru w latach 1464-1495. K. Latak, Kongregacja krakowska Kanoników Regularnych Laterańskich na przestrzeni dziejów, Kraków 2002, s. 188 nn; K. Łatak, Poczet rządców Opactwa Bożego Ciała Kanoników Regularnych Laterańskich w Krakowie, Kraków 2005, s. 41 nn.

${ }^{31} \mathrm{Tj} .18$ maja. 


\section{BIBLIOGRAFIA}

\section{Źródla}

Archiwum Narodowe w Krakowie

Perg. 887, Perg. 898.

Biblioteka Jagiellońska

Rkp. Dypl. 387.

Jan Długosz, Roczniki czyli kroniki sławnego Królestwa Polskiego, księga 12, Warszawa 2009.

\section{Opracowania}

Bielak Włodzimierz, Devotio moderna w polskich traktatach duszpasterskich powstałych w środowisku krakowskim do połowy XV wieku, Lublin 2002.

Kumor Bolesław, Dzieje diecezji krakowskiejdo roku 1795, t. 1, Kraków 1998.

Kuraś Stanisław, Słownik historyczno-geograficzny województwa lubelskiego w średniowieczu, w: Dzieje Lubelszczyzny, red. T. Mencel i in., t. 3, Warszawa 1983.

Kurtyka Janusz, Tęczyńscy - studium z dziejów polskiej elity możnowładczej w średniowieczu, Kraków 1997.

Łatak Kazimierz, Kongregacja krakowska Kanoników Regularnych Laterańskich na przestrzeni dziejów, Kraków 2002.

Łatak Kazimierz, Poczet rządców Opactwa Bożego Ciała Kanoników Regularnych Laterańskich w Krakowie, Kraków 2005.

Puławski S., Katalog czyli kronika opatów xx. cystersów w Koprzywnicy, „Kronika Diecezji Sandomierskiej”, 4 (1911) nr 5, s. 135-143.

Słownik Geograficzny Królestwa Polskiego i Innych Krajów Słowiańskich, red. B. Chlebowski i in. t. 1-15, Warszawa 1880-1914.

Zielińska Ewa, Kultura intelektualna kanoników regularnych z klasztoru w Kraśniku w latach 1469-1563, Lublin 2002. 


\title{
THE FOUNDATION DOCUMENT OF THE MONASTERY OF THE CANONS REGULAR OF THE LATERAN IN KRAŚNIK
}

\begin{abstract}
Summary
The paper presents the critical edition of the foundation document of the monastery of the Canons Regular of the Lateran in Kraśnik, issued by Jan Rabsztyński (the Topór coat of arms) on 18 May 1468. In this document the founder asks the Bishop of Cracow Jan Lutek of Brzezia to transform the parish church in Kraśnik into a monastic church of the Canons Regular. The article includes the detailed description of the monastery's emoluments. The drawer of the document showed the links between the Kraśnik monastery and the Corpus Christi Monastery in Cracow.
\end{abstract}

Keywords: Kraśnik; the Canons Regular of the Lateran; the Tęczyński family; Jan Rabsztyński; Jan Tęczyński; Jan Lutek of Brzezia 